\title{
Metastatic Prostate Carcinoma
}

National Cancer Institute

\section{Source}

National Cancer Institute. Metastatic Prostate Carcinoma. NCI Thesaurus. Code C8946.

A carcinoma that arises from the prostate gland and has spread to other anatomic sites. 